\title{
Successful outcome of pregnancy in uncorrected tetralogy of fallot with pulmonary atresia
}

\author{
Mugdha Laxmanrao Jungari*, Vilas N. Kurude
}

Department of Obstetrics and Gynaecology, Grant Government Medical College and Sir J. J. Group of Hospitals, Mumbai, Maharashtra, India

Received: 10 July 2016

Accepted: 05 August 2016

\section{*Correspondence:}

Dr. Mugdha Laxmanrao Jungari,

E-mail: dr_mugdhajungari@yahoo.co.in

Copyright: () the author(s), publisher and licensee Medip Academy. This is an open-access article distributed under the terms of the Creative Commons Attribution Non-Commercial License, which permits unrestricted non-commercial use, distribution, and reproduction in any medium, provided the original work is properly cited.

\begin{abstract}
Tetralogy of fallot (TOF) is one of the commonest congenital anomalies. TOF is mostly diagnosed early in the life and to reach adulthood, such patients usually require some sort of surgical correction. Management of pregnancy in uncorrected TOF cases poses a significant challenge for obstetrician and team. Most of the time, it ends with significant fetomaternal morbidity or mortality. Here is a case of pregnancy with uncorrected TOF, which was successfully managed with multidisciplinary approach.
\end{abstract}

Keywords: Uncorrected tetralogy of fallot, Pregnancy, Management and complications, Outcome

\section{INTRODUCTION}

Tetralogy of fallot (TOF) is the most common type of cyanotic congenital heart disease. The defects which can be found in patient with TOF are caused by a single developmental defect: an abnormal anterior and cephalad displacement of the infundibular (outflow tract) portion of the inter-ventricular septum. Four anomalies arising from this defect are pulmonary stenosis, right ventricular hypertrophy, overriding aorta and non-restrictive ventricular septum defect. ${ }^{1,2}$ The prevalence of congenital heart defects within India is approximately 4 cases per 1,000 live births with TOF comprising 7 to $32 \%$ of these cases, making it among the most common congenital anomalies. ${ }^{3}$

In the present era of ultrasonography, majority of these patients are diagnosed in intrauterine life, and most are identified and treated in first year of their life. ${ }^{4,5}$ To reach adulthood, patients with TOF need surgery, either palliative or reparative. However, few patients (only 3\%) may reach adulthood or till fourth decade of life without correction of TOF. Uncorrected TOF in pregnancy is a rare entity; with few cases reported till date. Most of the cases reported, are from developing countries; possibly because of lack of awareness and resources for correction of this congenital anomaly at an early age. Because of significant physiological adaptations and changes, pregnancy and delivery process are troublesome for mostly unhealthy women, including those with uncorrected TOF. Patients with uncorrected TOF may deteriorate during pregnancy, labour and puerperium. This remain an important cause of maternal morbidity $(62.5 \%)$ and even mortality (10\%) and have significant effects on foetal outcome. ${ }^{6}$ Management of these cases poses a significant challenge for the obstetrician, cardiologist and the anaesthetist partly due to rarity of cases and paucity of literature.

\section{CASE REPORT}

A 30 year woman with secondary infertility came to our institutional obstetrics outpatient department for consultation. On physical examination, she was having clubbing and bluish dark coloured skin. Incidentally during routine investigations and fitness for future 
procedures, she was diagnosed as a case of uncorrected TOF physiology with large perimembranous VSD with RVOT; outflow could not be visualized (pulmonary atresia). By this time, she conceived spontaneously and even after explaining moderate risk to her during pregnancy, she chose to continue.

The patient, married at the age of 20 years had 2 abortions. During her first pregnancy, she underwent MTP at 2 months gestation for some personal reason. After 6 years she conceived and had spontaneous first trimester abortion. Patient was anxious to conceive since then. She also had past history of pulmonary Koch's, completed 6 months AKT.

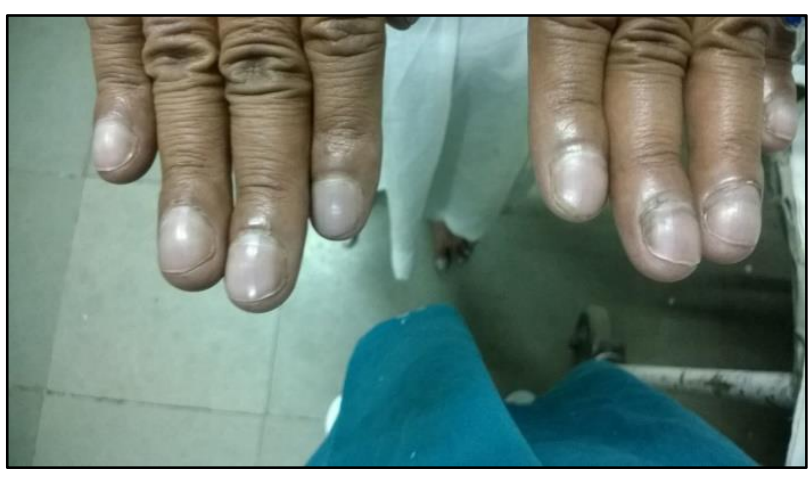

Figure 1: Clubbing in hands.

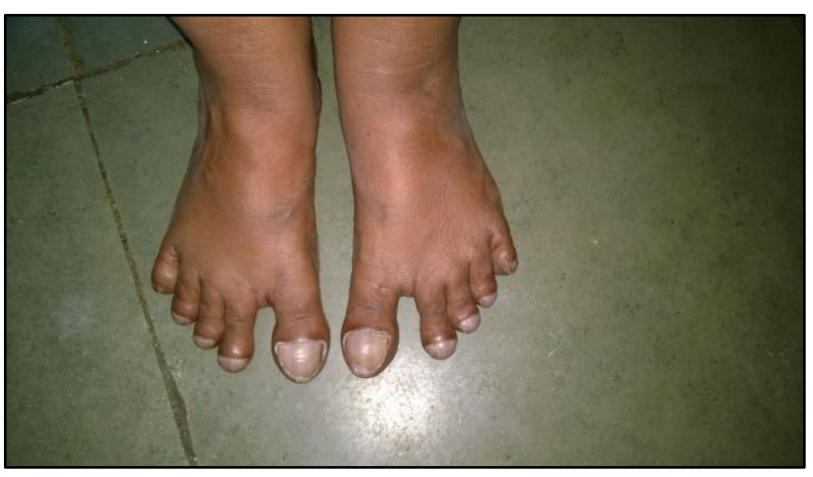

Figure 2: Clubbing in feet.

\section{Course in the hospital}

The Patient registered in antenatal clinic and was on regular follow up. At the time of first ANC visit her weight was $34 \mathrm{~kg}$ (BMI18). She was admitted at 16 weeks of gestation because of bilateral pedal oedema, cyanosis of lips, oral mucosa fingers toes and recurrent respiratory tract infections. However, her vitals were normal. $\mathrm{O}_{2}$ saturation was $85 \%$ on room air. She had polycythemia with haemoglobin of $17 \mathrm{gm} / \mathrm{dl}$. Fetal 2D ECHO and bilateral lower limb venous Doppler was within normal limits. Patient was admitted again at 26 weeks of gestational age with dyspnoea (NYHA grade II) and haemoptysis. Cardiologist advised her tablet tranexamic acid and ambulatory oxygen therapy. Patient then improved symptomatically and was kept admitted for intensive ANC monitoring. Periodical obstetric ultrasonography doppler, routine blood investigations were done. At 28 weeks of gestation, obstetric USG Doppler suggested feto-placental insufficiency. To achieve fetal lung maturity, 2 doses of Injection Betamethasone were administered. At 32 weeks of gestation age, there was a fetal growth lag of 4 weeks (USG GA-27 weeks and 2 days) with oligohydraminos with moderate to severe utero-placental and fetoplacental compromise with brain sparing effect. Indication of fetal distress on routine NST prompted the doctors to undertake patient for emergency LSCS on 6/2/16 (32 weeks 1 days GA) under general anaesthesia. The newborn was shifted to NICU in view of severe low birth weight (weight $1 \mathrm{~kg}$ ). The patient was shifted to critical care unit (CCU) for observation and on 4th day, she was shifted to PNC ward.

On Day 7 post-partum period, the patient developed altered sensorium, CT Brain was s/o white matter edema with effacement of adjacent sulci. After a week of CCU monitoring for altered sensorium, the patient's condition improved and patient was shifted to back to PNC ward.

\section{Course of newborn}

The 2D ECHO of newborn was s/o of cyanotic congenital heart disease (CCHD) with $6 \mathrm{~mm}$ OS ASD with $2 \mathrm{~mm}$ VSD e/o PAH. During the stay in NICU, baby gained weight and was discharged at 10 weeks of life, with $2 \mathrm{~kg}$ weight and improved $2 \mathrm{D}$ ECHO findings (acyanotic congenital heart disease with $5.4 \mathrm{~mm} \mathrm{ASD}$ and $2.7 \mathrm{~mm}$ sub aortic VSD with no significant PAH).

\section{DISCUSSION}

Long survival of TOF patient without any surgical correction is rare and pregnancy in a case of uncorrected TOF is even rarer. Undiagnosed and uncorrected TOF may present with cyanosis, which is often difficult to notice in dark coloured Indian population. This woman didn't give any history s/o cardiac problem or she concealed the fact from the treating obstetrician. During pregnancy, vasodilatation leads to fall of peripheral vascular resistance, resulting in increased right to left shunt. So, there is reduction of pulmonary blood flow and increase in aortic blood flow, which further leads to reduction of arterial $\mathrm{O}_{2}$ pressure and its saturation, which worsens cyanosis and hypoxia during pregnancy. ${ }^{2,7,8}$ This explains why this patient became more symptomatic during pregnancy. Chronic hypoxemia leads to increased RBC mass (polycythemia), fetal growth restriction (FGR) and increased pulmonary vascularity, which may result in haemoptysis as seen in this patient.

Uncorrected TOF is a life threatening condition for both mother and fetus. The management in case should be focused on maintaining the oxygen saturation to avoid hypoxemia and subsequently keeping the polycythemia, thrombocytopenia in check. Along with this, such 
patients should be followed up regularly with complete hemeogram and ultrasonography for antenatal fetal surveillance.

Studies have shown that gestation increases mortality and morbidity rates of uncorrected TOF patients, especially those with history of syncope, polycythemia and right ventricular hypertrophy. Risk is increased when arterial oxygen saturation level at rest is below $85 \%$ and haemoglobin level $>20$ gm $\%$. $^{9}$ During postpartum period, there are chances of hypoxia and volume overload, which may worsen the cardiac functions. As seen in this patient, there was altered sensorium due to cerebral edema, which may have resulted from hypoxia during postpartum period.

\section{CONCLUSION}

A case of pregnancy in patient with uncorrected TOF has been discussed above. The patient was diagnosed, TOF with class II of NYHA grade dysopnea and secondary polycythemia caused by hypoxia during pregnancy. The management of such patients are with total bed rest, oxygen therapy and tranexamic acid for haemoptysis. Because of this, we were able to keep oxygen saturation above $85 \%$ and haemoglobin around $15 \mathrm{gm} \%$ and there was no thrombocytopenia. The favourable outcome was possible because of continuous monitoring and availability of critical care facility for both mother and new-born, after emergency caesarean section. However, this ideal management may not be possible in many resource limited settings in India, where it's not possible to keep the patient under observation for so many days and unavailability or inaccessibility of critical care facility with cardiology and radiology departments. In such situation the prognosis of pregnancy in patient with uncorrected TOF is often poor.

\section{ACKNOWLEDGEMENTS}

The authors appreciate the efforts put by medical staff of Obstetrics and Gynaecology, General Medicine,
Cardiology, Anaesthesia department of GGMC and Sir J J Group of hospitals Mumbai, who played a vital role in successful management of this patient.

Funding: No funding sources

Conflict of interest: None declared

Ethical approval: Not required

\section{REFERENCES}

1. Therrien J, Webb GD. Congenital heart disease in adult. In: Braunwald E, Zipes DP, Libby P, eds. Heart disease: a textbook of cardiovascular medicine. $6^{\text {th }}$ ed; 2001:1605-7.

2. Sankaran VG, Brown DW. Congenital heart disease. In: Lilly LS, ed. Pathophysiology of heart disease. $4^{\text {th }}$ ed. Baltimore: Lippincott Willimas and Wilkins; 2007:390-3.

3. Saxena A. Congenital heart disease in India: a status report. Indian Journal of Pediatrics. 2005;72:595-8.

4. Semeraro O, Scott B, Vermeersch P. Surgical correction of tetralogy of fallot in a seventy-five year old patient. Int J Cardiol. 2008;128:98-100.

5. Bailliard F, Anderson RH. Tetralogy of fallot. Orphanet J Rare Dis. 2009;4:2.

6. Veldtman GR. Outcomes of pregnancy in women with tetralogy of fallot. J Am Coll Cardiol. 2004;44:174-80.

7. Elyakam U. Pregnancy and cardiovascular disease. In: Braunwald E, Zipes DP, Libby P, eds. Braunwald's Heart Disease: A Textbook of Cardiovascular Medicine. $6^{\text {th }}$ ed. Philadelphia: W.B. Saunders; 2001:2172-2177.

8. Cunnigham FG. Cardiovascular disease. In: Rouse D, Rainey B, Spong C, Wendel GD, eds. Williams Obstetrics. $23^{\text {rd }}$ ed. New York: McGraw-Hill Companies; 2005:963-970.

9. Presbitero P, Somerville J, Stone S. Aruta E, David S, Rabajoli F. Pregnancy in cyanotic congenital heart disease. Outcome of mother and fetus. Circulat. 1994;89:2673-6.

Cite this article as: Jungari ML, Kurude VN. Successful outcome of pregnancy in uncorrected tetralogy of fallot with pulmonary atresia. Int J Reprod Contracept Obstet Gynecol 2016;5:3235-7. 